\title{
Point-of-care C-reactive protein testing service for respiratory tract infections in community pharmacy: a qualitative study of service uptake and experience of pharmacists
}

\author{
Petra Czarniak $^{1}$ (D) $\cdot$ Leanne Chalmers $^{1}$ (D) . Jeffery Hughes ${ }^{1}$ (D) $\cdot$ Rebecca lacob $^{1}$ (D) $\cdot$ Ya Ping Lee $^{1}$ (D) Kiran Parsons $^{1}$ (D) .

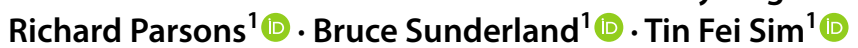

Received: 21 September 2021 / Accepted: 15 December 2021 / Published online: 28 January 2022

(C) The Author(s), under exclusive licence to Springer Nature Switzerland AG 2021

\begin{abstract}
Background Targeted interventions in community pharmacies, such as point-of-care C-reactive protein testing, could reduce inappropriate antimicrobial consumption in patients presenting with symptoms of respiratory tract infections, although data regarding Australian pharmacists' perspectives on its provision are limited. Aim To explore pharmacists' experiences and perspectives of point-of-care C-reactive protein testing, including barriers and facilitators, influencing service provision and uptake. Method A point-of-care C-reactive protein testing service for patients presenting with respiratory tract infection symptoms was trialled in five purposively selected community pharmacies in metropolitan Western Australia. Two pharmacists from each pharmacy participated in one-to-one semi-structured telephone interviews, regarding pharmacist demographics, pharmacy characteristics, experience with the point-of-care C-reactive protein service and training/resources. Interviews were audio-recorded and transcribed. Data were imported into NVivo for thematic analysis. Results Interview durations ranged from 28.2 to $60.2 \mathrm{~min}$ (mean: $50.7 \pm 10.2 \mathrm{~min}$ ). Of the five themes which emerged, participants reported the point-of-care C-reactive protein testing was simple, fast, reliable and accurate, assisted their clinical decision-making and contributed to antimicrobial stewardship. A major factor facilitating service provision and uptake by consumers was the accessibility and credibility of pharmacists. Barriers included time constraints and heavy documentation. Participants believed there was a public demand for the service. Conclusion Given the global antimicrobial resistance crisis, pharmacists have an important role in minimising the inappropriate use of antimicrobials. The point-of-care C-reactive protein service was readily accepted by the public when offered. However, ensuring efficient service delivery and adequate remuneration are essential for its successful implementation.
\end{abstract}

Keywords Antimicrobial stewardship · C-Reactive protein · Clinical decision-making · Professional pharmacy services · Point-of-care testing $\cdot$ Respiratory tract infections

\section{Impacts on practice}

- Provision of a point-of-care C-reactive protein testing service in community pharmacies is a valuable addition to pharmacists' clinical decision making in managing

Petra Czarniak

P.Czarniak@curtin.edu.au

1 Pharmacy, Curtin Medical School, Faculty of Health Sciences, Curtin University, Kent Street, Bentley, WA 6102, Australia respiratory tract infections and can contribute to antimicrobial stewardship.

- Point-of-care C-reactive protein testing is simple, reliable and fast, better engaging patients in shared decision-making about management of their respiratory tract infections

- While ease of access to the service and the credibility of pharmacists can facilitate service provision and uptake, key barriers include time constraints and remuneration 


\section{Introduction}

In keeping with international trends, community pharmacy in Australia has evolved to a rapidly changing landscape and paradigm shift in practice, from mainly dispensing and supply, to increased provision of professional services, including primary health care, advice and support, education for consumers on the use of medicines, health promotion and disease prevention [1]. Ease of accessibility to community pharmacies makes this practice setting an ideal 'health hub destination' for the public [2]. In many countries, including Australia, the United Kingdom (UK), Canada, New Zealand and the United States of America (USA), community pharmacies provide enhanced services including blood pressure monitoring, smoking cessation, weight reduction, vaccinations and medicines reviews [3-5]. Pharmacists regularly provide over-the-counter (OTC) treatment and management advice for minor ailments, including respiratory tract infections (RTIs), where recommendations are typically based on presenting signs and symptoms, rather than diagnostic tests [6,7]. Currently, there are limitations to the management of RTIs in community pharmacy settings, as diagnosis based solely on signs and symptoms is unable to differentiate between viral and bacterial infections [8].

Although most RTIs are of viral origin, more than $60 \%$ of patients with RTIs are prescribed antimicrobials by general practitioners (GPs) in Australia [9-11]. Antimicrobial resistance (AMR) is recognised globally as an important health threat, causing increased morbidity and cost. Factors for the development of AMR are mainly overuse and inappropriate use of antimicrobials [12]. Despite initiatives to decrease antimicrobial use, substantial increases in global antibiotic consumption are reported [9, 11, 13]. Efforts to optimise the use of antimicrobials have focused on antimicrobial stewardship (AMS) programs in hospitals with limited initiatives in the primary care setting [14]. Targeted interventions in community settings could have a large impact on reducing antimicrobial consumption, especially for those with RTIs [2].

C-reactive protein (CRP) is the most suitable biomarker to guide the use of antibiotics in RTIs [15]. CRP is an acute marker of inflammation [16]. Levels of CRP can increase dramatically in response to inflammation, infection or injury [17]. The National Institute for Health and Care Excellence (NICE) recommends that point-of-care (POC) CRP testing should be considered when an individual presents with RTI symptoms [18]. POC CRP testing has been implemented successfully in primary care settings in the UK and several European countries, including Belgium, Spain, Poland and the Netherlands [19, 20], to differentiate bacterial from viral infections, potentially reducing unnecessary antibiotic prescribing [21-24].
A feasibility study of POC CRP testing was recently undertaken in Western Australian community pharmacies to support pharmacists' management of RTIs [25]. Many participants presenting with symptoms of RTI had CRP levels less than $5 \mathrm{mg} / \mathrm{L}(60 / 131 ; 45.8 \%)$ and when provided with a CRP result, changed their perceptions about the need for antibiotics [25]. All participants were satisfied with the POC CRP testing service and most reported they would use it again. Although several other POC tests, including plasma lipids [26], blood glucose [27] and international normalised ratio [28], have been offered in some Australian community pharmacies, data on facilitators and barriers to implementing POC testing are limited. Both national [29] and international [30] pharmacy organisations recognise a role for community pharmacy in POC testing into the future, however, it is not known whether facilitators and barriers reported in other conditions would be similar [1, 4, 31-34]. It is therefore important to obtain the experiences of community pharmacists in the provision of POC testing, and factors that may influence widespread implementation of such services in the Australian community pharmacy setting. Additionally, the significant AMS potential of POC CRP testing, made a 'novel' POC testing service worthy of evaluation.

\section{Aim}

This study aimed to explore pharmacists' experiences and perspectives, including barriers and facilitators to service provision and uptake by consumers, regarding the implementation and sustainability of POC CRP testing in RTI management in purposively selected community pharmacies in Western Australia (WA).

\section{Ethics approval}

Curtin University Human Research Ethics Committee approved the study (HRE2019-0139; 21/03/2019) and included on the Australian New Zealand Clinical Trials Registry (ACTRN12619000965101).

\section{Method}

This qualitative study forms part of a larger feasibility study which trialled a POC CRP testing service ('the service') in five purposively selected community pharmacies in metropolitan WA, selected from 126 pharmacies responding to an expression of interest, based on pharmacy location, size, available facilities and model of operation [25]. Purposive selection allowed for maximum variation in the sample to enable in-depth inquiry into pharmacists' experiences and perspectives of the service from a range of pharmacies.. In keeping with qualitative methodology, this approach was 
followed to improve credibility and reliability, and to obtain information rich data [35]. The study was conducted over an eight-week period from June to August 2019 coinciding with the influenza season in Australia. Each pharmacy was required to recruit 25-30 adult patients, details of which are described elsewhere [25].

\section{Design and setting}

Qualitative data were obtained from in-depth one-to-one semi-structured telephone interviews using a census sample of 10 champion pharmacists based in the participating community pharmacies, to gain an in-depth understanding of pharmacists' experiences and perspectives about the study and provision of 'the service'. The development, analysis and reporting of this pilot study followed qualitative research criteria [36].

\section{Interview tool and data collection}

A semi-structured interview tool was developed, comprising of four parts: Part A-Pharmacist professional experience/roles; Part B-Pharmacy characteristics; Part C-Experiences with the POC CRP service; and Part D-Training and resources. The interview tool was face validated by four academics/pharmacists; two research team members were involved with a practice run. To avoid bias and assumptions, all interviews were conducted by the research assistant (RI), a female pharmacist involved in the implementation of 'the service' within the feasibility study and with extensive pharmacy experience. The experience of the interviewer allowed appropriate digression to enable collection of informationrich data. Following consent from participating pharmacists, audio-recorded interviews were conducted and transcribed verbatim by a professional transcription service. Transcripts were not returned to participants for participant checking. Transcripts were de-identified by replacing participants' identities with specific codes. For example, 'PO1-A' denoted participant number 1 who practised in Pharmacy A. All interviews and analyses were conducted between September 2019 and February 2020. Participants were reimbursed AUD\$50 for participation.

\section{Data analysis}

De-identified transcripts were imported into NVivo version 12 Pro for subsequent organisation and thematic analysis. Two experienced qualitative researchers (TFS and PC), both academic pharmacists involved in the implementation and evaluation of the pilot study, inductively analysed the data independently to identify themes. To gain an in-depth understanding of the topics discussed, the researchers read the transcripts repeatedly before ideas were coded as 'nodes'.
Nodes were then grouped to form a working coding framework. Subsequently codes were grouped into categories to form sub-themes and themes. The two researchers met to agree on themes. Conflicts were resolved by discussion until a consensus was reached. Triangulation was informed with findings from a previous study [25].

\section{Results}

All pharmacists agreed to be interviewed. Data saturation was reached after six interviews, however, all 10 pharmacists who were engaged with the feasibility study, were interviewed. Interviews with the other four pharmacists did not result in any additional themes, confirming data saturation (ie no new themes emerging). The duration of interviews ranged from 28.2 to $60.2 \mathrm{~min}$ (mean: $50.7 \pm 10.2 \mathrm{~min}$ ). Demographic characteristics of participants and their practice settings are summarised in Table 1. Most of the participants were female $(8 / 10 ; 80 \%)$. The mean age was 36 years (range: $22-53$ years), with half $(5 / 10 ; 50 \%)$ aged between 31 and 35 years. Years of practice experience ranged from one to 32 years (mean: $13.1 \pm 11.1$ years; median: 9.0 years).

Five main themes emerged through thematic analysis:

- Enhanced service provision

- Decision-making and AMS

- Facilitators to successful service delivery

- Barriers and challenges

- Public demand for ongoing provision

\section{Enhanced service provision}

Pharmacists perceived 'the service' as a well-structured opportunity to explore the provision of a new professional service, stating that it broadened the scope of pharmacy practice. The service was perceived as simple, reliable, fast and accurate, and that the test result and its interpretation provided valuable information to the consumer about their health, which would not be provided if they had gone straight to their GP:

It just adds to our ability to help them when they come in asking for something for an upper RTI. It gave us an opportunity to improve our services.... (PO1-A)

As pharmacists are freely accessible, they are often the first point of call. Many felt they played a huge role in primary healthcare as frontline workers by providing services that were attractive to the public and within their scope of practice. They reported that POC CRP testing assisted them to triage consumers more appropriately and either refer them to their GP for antibiotics if needed or prevent unnecessary 


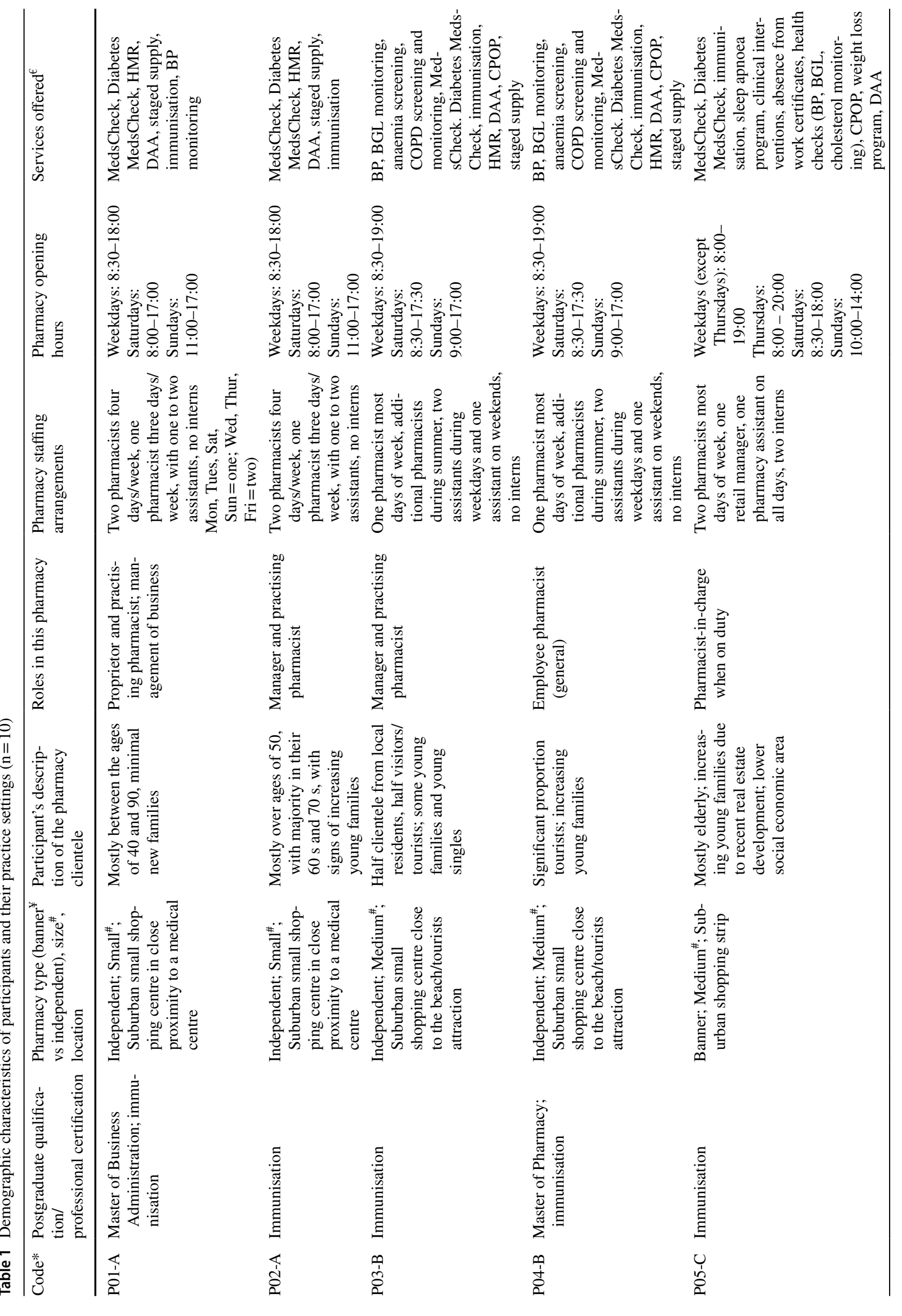




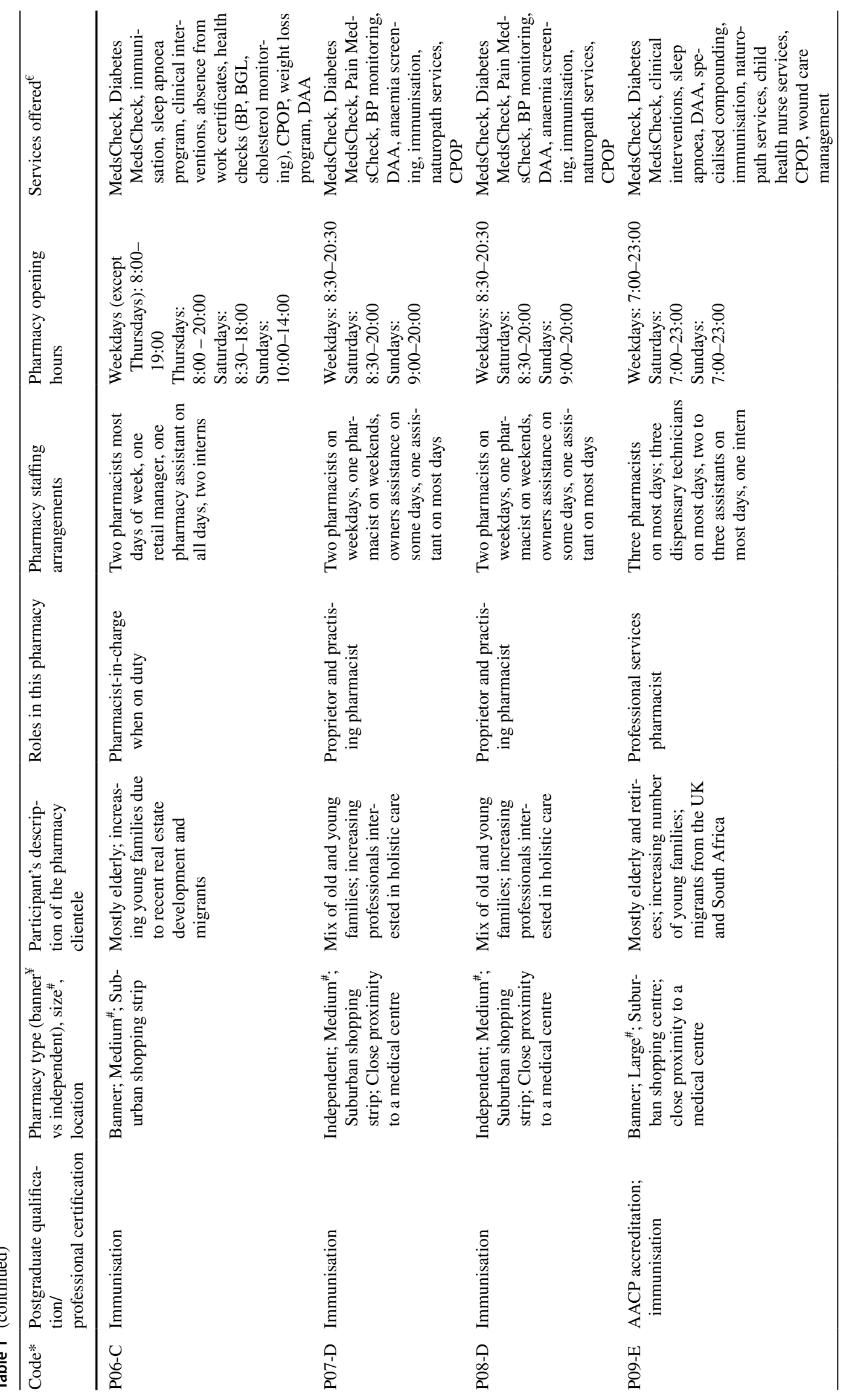




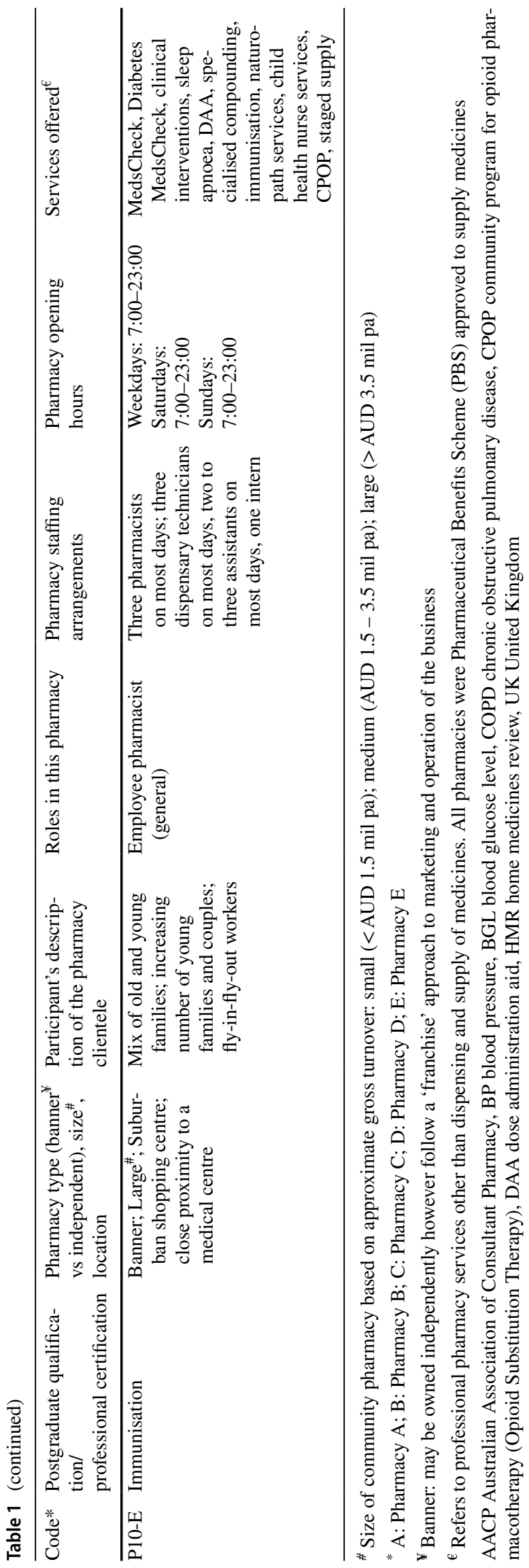

antibiotic prescribing, as exemplified by the following comments:

We're their first stop before they go see a doctor for anything... we can sort of say, "... your CRP is higher than it should be. You're going to need antibiotics or make an appointment with the doctor." (PO2-A)

[Patients]...bring up other things like "my blood pressure's been a bit all over the place'. Being able to be so freely accessible, I think we've really got a huge role in the health industry, because we are front line. (PO8-D)

Pharmacists reported that the process of POC CRP testing was professional and improved pharmacists' professional image (Table 2). They also reported increased consumer engagement, with consumers returning to the pharmacy, seeking advice on other health related issues. Several reported they had attracted new clientele. Pharmacists considered that the clientele perceived them to be knowledgeable, supportive and able to provide tools to improve their health.

It gave us an opportunity to appear very professional the way it was done. With the gloves, and the alcohol wipe and everything, it was very professional how we did it... was ... a good image for us... professional. (PO1-A).

Further, some reported that the provision of 'the service' enabled an improvement in their professional relationship with their local GPs. In one case, the doctor referred the patient to the pharmacist for CRP testing.

\section{Decision-making and antimicrobial stewardship}

Pharmacists reported that 'the service' assisted their clinical decision-making and recommendations. They felt reassured they could confidently advise consumers they were likely experiencing a viral infection based on' the service' result, providing good consumer satisfaction. The consumer was then more likely to trust the pharmacist regarding the recommendation for an OTC product:

...we get something out of every CRP testing because that allows us to make a decision more confidently, and patients are now convinced about the type of preparations or the type of products that we recommend. (PO3-B)

Several pharmacists reported that consumers saw value in 'the service' because it provided both the pharmacist and consumer with a better insight to their condition, and allowed consumers to make a conscious decision about the appropriateness of antibiotics. Several pharmacists reported that consumers had booked a GP's appointment but 
Table 2 Facilitators and barriers to the provision of point-of-care C-reactive protein testing

Facilitators Verbatim quotes

Accessibility

Enhance relationships with general practitioners

Improved professional image and strengthened existing or established new pharmacist-patient relationships

Marketing and promotion to encourage service uptake

Practice and experience promotes confidence
"It [the pharmacy] services its local community very, very well. It has been there a long time, so it has got a reputation in the area. And it tends to be a point of contact for information as well as products and services...the fact that we are so accessible and we don't need appointments ... without having to sit in a room of other people that were really unwell like you do at a surgery." (PO7-D)

"They get good advice... being able to be so freely accessible, I think we've really got a huge role in the health industry, because we are front line. And people always come in for advice...And we have the capacity to be able to do that." (PO8-D)

"Our next-door GP was really impressed that it was happening, and she thought it was a great service. I sent one person into her because... [they] had an elevated...level. But it wasn't highly elevated-a bit high- wanted to also show her how the system worked and how it can lead to referrals. And she said to the patient, "Yes...the pharmacist is right. It's not high, but there might be something on its way, so come back in a few days," and things like that. So it was good." (PO7-D)

"They'll come in and ask us medical-related questions about things which I didn't expect them to be asking." (PO2-A) "I think it helped build... trust in our services." (PO4-B)

"And so it's definitely been interesting to see the people that participated come back and people that had never presented to our pharmacy before, now becoming regulars because they appreciated the fact that you sat with them and had that conversation and gave them the support and tools that they needed to be able to get better." (PO10-E)

"I thought it was great to interact with our patients at that level and offer them a service that they really appreciated and that they valued...very positive. They [patients] appreciated it, and were really happy to get that sort of information ... without having to make an appointment, without having to wait as well, and without having to sit in a room of other people that were really unwell like you do at a surgery. It also gave you that added interaction with your patient as well, which is really important to follow up." (PO7-D)

"...market it out, let all the doctors know in the surgery, not just across the road, but with all our local ones, as well. I feel that would have been a better uptake. But also if we had been able to market it out to the public openly, on all the social media platforms." (PO9-E)

"I think that there's a public need for 'the service', one, because it's not being offered anywhere else and two because ... a lot of people were asking, "Why doesn't this get offered to me when I see my GP? Or ..."I didn't realise there could be a test that was this fast and this accessible that I could do. The flyers and the things in the pharmacy helped a lot and a lot of people were like, "Oh, what is this test? Tell me about CRP." And just getting people, I guess, engaged in that conversation was pretty important." (PO10-E)

"...getting to learn how to use it...it's a bit tricky...it's just getting the right amount of blood and making sure the machine is working and stuff. But once you get the hang of it, it's very simple to do. So our times of actually doing the test started reducing, which is great because then the patients knew our time." (PO2-A)

“... after you do the first one or two people... I know how to do this service in a way that works for me. I understand how...it's integrated into the conversations I'm already having with people...felt more confident." (PO10-E) 
Table 2 (continued)

Facilitators

Supportive team

Verbatim quotes

"Staff members were all engaged to see if anyone fits into the criteria that this study was looking for and alert us, or they actively offered 'the service' and let us know if the patient wanted it done. Once they started seeing how people can benefit from it and once they heard feedback from patients about how great they were to have this testing done, I think they become a bit more involved." (PO3-B)

"everything just flowed a lot better, especially as the other staff...got used to explaining 'the service' and recommending it as well to our customers. So they obviously had to be familiar with what was involved in it, how much time it took.." (PO4-B)

“...it's not physically possible to catch everybody. But if your assistants or your dispensing technicians are aware of what to look out for, they can collect more people." (PO10-E)

Barriers or challenges

Challenging interactions with general practitioners

Competing demands

Difficulty in follow ups

Early stage of disease may not be reflected in CRP reading
Verbatim quotes

"GP's don't make an email address available, and if they did, it would be so much easier because you could just email them and say what the problem is." (PO1-A)

“... doctors' unwillingness to engage.” (PO3-B)

“...quite a few only work one, two days a week. So it's hard to contact them ... Sometimes they're not there to have that discussion." (PO5-C)

"He's told me he's the doctor; I'm the pharmacist before. He's just from the old school." (PO6-C)

“... barrier would be receptionists... think there's also that part whereby GPs don't see the importance of communicating with pharmacists." (PO9-E)

“...what's tricky is when you're communicating to the practice manager and sometimes no information gets across to the GPs. But if you speak to the GP directly, that information then gets across. And I think that's where the relationship starts." (PO10-E)

"...we were just flat out with flu bookings...we were sort of run off our feet." (PO5-C)

"At the beginning, it was sort of the end of the flu season. So we were backlogged with work with just trying to catch up on everything." (PO6C)

"...too much is happening within the pharmacy ...we had QCPP (Quality Care Parmacy Program) as [CRP testing] was starting." (PO8-D)

"A couple of people ... were on the mines. So on the day we had to follow up, we couldn't get in touch with them, and then I had to follow up a couple of days later." (PO2-A)

"Some of them did not reply." (PO3-8)

"They wouldn't return calls so we weren't always getting that final section completed on the form....an email or a text service might work better." (PO4-B)

"The follow-up was fine. We had a bit of trouble reaching some of them, but that's just norm." (PO5-C)

"Getting in contact with them again in a couple days time was the trickiest...I just think that people don't answer phone numbers they don't recognise... a few people were going overseas. They requested to email them as opposed to calling them." (PO6-C)

"Perhaps maybe a text message...more would be more inclined to answer a text message at their own convenience, rather than try to answer a phone call halfway through work...Email, probably not. Probably a text message would be better." (PO9-E)

"We just put in prompts in there to remind us to contact people back." (PO10-E)

"We were testing too early in the course of the disease. So if we had been able to say to the person, "Come back again in two days, and we'll test you again," I think that might've been a bit easier." (PO1-A) 
Table 2 (continued)

Barriers or challenges

Heavy documentation

Inadequate remuneration to justify multiple pharmacists at one time

Perspectives of patients - bulk billing from general practitioners
Verbatim quotes

"When people hear, that they have to do some form of paperwork and when they're sick...straightaway turned off.." (PO5-C)

"I did find that there was still a lot of paperwork and that it took quite a bit of time as far as the waiting time for the machinery. And I had a few people say to me, "Oh, look, I've gotta go. I've gotta go," and even though it's a short period of time and I've got them to do the paperwork at the time... although it was an opportunity to talk about their conditions and things...logging in and the recording of the name was a bit laborious." (PO7-D)

"I'm the owner, and I don't necessarily draw a wage all of the time, but I couldn't afford to have two pharmacists on for the rest of the time. If they [assistants] could actually do the actual blood test, and then us interpret the results that would've been a bit easier, especially for an intern." (PO1A)

"....it takes up quite a bit of staff time. Staffing can be an issue,... we can't predict when it's going to get busy." (PO3-B)

"...it's always so unpredictable the flow of traffic that you get in the pharmacy...taking around $15 \mathrm{~min}$. It could take longer as well." (PO4-B)

"On top of the cost of covering the equipment and consumables, I think only a small fee...to cover the time and sort of services. Who should pay? Sometimes they will pay. I guess personally, the government should pay in terms of to try and decrease that burden in the healthcare system. That would be foremost." (PO5-C)

"There's these little bulk billing GPs popping up everywhere. Why would you go to a pharmacy and pay something if you could just go to the doctor for nothing." (PO6-C)

"Rather than you assess me and I have to pay 15 dollars, I can just go across the road, book an appointment, and the doctors will assess me, and it's the same outcome. And that will be covered by Medicare, although it's not exactly the same outcome, because you don't have a lab test sort of result to accompany you, but to them, a doctor's assessment is judged as gold." (PO9-E) following the outcome of the CRP test, it provided evidence for them that antibiotics were unlikely to be beneficial so they cancelled their GP's appointment:

I had a lady who was going on holidays, and...she said, "The doctor's given me antibiotics to take, but I don't like taking them. I really don't know whether I should or not because she [doctor] said not to take them unless I needed them." So we were able to show her where she was at the time. (PO7-D)

Pharmacists were aware of the global AMR health threat, with some commenting that antibiotics were overprescribed. They perceived 'the service' had contributed towards AMS and reduced unnecessary antibiotic use:

We had a lady who being on antibiotics a couple of weeks before, thought she was better. She came in and she thought, "Oh, no. I've got it again." And we said, "No. Look. Let me have a look and make sure it's not a secondary viral infection after you've had the first one." Her CRP was normal and she thought maybe it's just the virus carrying on. So she got more cold and flu tablets and she came back, "Thank you guys so much. You just saved me a trip to the doctor again." Just helping the community because you're reducing antibiotic use. (PO2-A)

Pharmacists recognised that many people who visit their GP expected to be prescribed antibiotics, although often unnecessarily:

We're seeing people who tend to overuse antibiotics far more often than they might have when I first qualified...people don't want to walk out of a doctor's appointment that they've just paid or not paid for without a prescription in hand...They're going to go fill it. (PO6-C)

While AMS is important to prevent unnecessary prescriptions of antibiotics, respondents also described situations when CRP testing sped up referral to a GP when antibiotics may have been warranted. Pharmacists were able to confidently refer patients when POC CRP testing values were higher than expected. 'The service' assisted with decisionmaking about whether antibiotics were justified in patients 
reluctant to take them. For example, in two scenarios (Table 3-Quotes 1\&2), where the consumer was reluctant to visit their GPs for antibiotics, the pharmacist persuaded the consumer to visit their GP due to the elevated CRP levels.

In one case (Table 3-Quote 3), a patient who visited their doctor because they had been unwell for a few weeks, was told they had a viral infection and antibiotics were not needed. Following the POC CRP testing at the pharmacy, the elevated CRP level prompted the pharmacist to refer the patient back to the doctor for antibiotics.

\section{Facilitators, barriers and challenges to successful service delivery}

A number of influential factors emerged from the interviews with some facilitating, and others posing challenges to, the success of service implementation and provision (Table 2). Factors facilitating service provision included the accessibility and credibility of pharmacists, having a supportive team, practice experience and marketing and promotion strategies to encourage service uptake.

Barriers to service provision and uptake included a lack of time and difficulty with rostering of pharmacists (as it was difficult to anticipate RTI presentations during service hours), both of which were linked to remuneration. Pharmacists reported they were often unable to contact a person by phone for follow-ups and a better option could be to send an SMS. Follow-up contact is not common practice in community pharmacy and would not normally be part of a service in every day practice. Some pharmacists reported challenging interactions with GPs and a lack of understanding by health professionals about 'the service'. Some reported that it was difficult to contact GPs, as they had limited shifts or the receptionist's unwillingness to allow the pharmacist to speak with the GP. Using the GP's email address or another secure mechanism of messaging GPs, could make interactions less challenging.

\section{Public demand for ongoing provision}

Despite the challenges and barriers, all pharmacists were supportive for ongoing provision of 'the service' and believed there is a public demand for such a service. All pharmacists expressed an interest in continuing with service provision beyond the study period.

I think there is a public need for this service...because my patients really valued it, and they said to me, "Oh, this is great. It would be great if we could have this all the time. (PO7-D)

I've seen in practice myself whereby people are overusing or underusing antibiotics. I think there is a public need for this service definitely... and the public need to be aware and need to understand that ... antibiotics is not always the answer... (PO9-E)

\section{Discussion}

To our knowledge, this is the first study investigating pharmacists' perceptions of a POC CRP testing service for consumers with symptoms of RTIs presenting to community pharmacies in Australia. Pharmacists perceived 'the service' to be within their scope of practice, and it offered an opportunity to impart valuable information to consumers. They reported that CRP testing gave them confidence in their clinical decision-making and built consumer trust. It led to high consumer satisfaction by providing a better insight into their clinical condition and allowed them to

Table 3 Examples of quotes related to antimicrobial stewardship

\begin{tabular}{l}
\hline Quote $\quad$ Details \\
\hline 1 \\
"She was traveling next day to Cambodia for a prolonged period of time and had less than 24 h to see a doctor...came in, did a test, and \\
she charted at quite a high CRP reading. So I referred her on to the GP...Another [was] one of our students who was unwell, went to \\
a GP, GP looked at her and said, "Did you want a medical certificate?" And she said, "I'm not here because of a medical certificate. \\
I'm fine with work, but actually feel unwell." Looked at her throat and said, "You don't look sick to me." She came into work and \\
requested that I do the test for her ... she charted really high numbers and it was an instant referral to the GP [who] diagnosed her \\
with possible strep throat and Ross River virus." (PO9-E) \\
"A gentleman that came in... was....reluctant to... see his GP...requesting a leave [medical] certificate... He had quite an elevated CRP \\
level which then ... gave me more ground to offer him a leave [medical] certificate...I... also gave him a referral to see his GP...he \\
ended up seeing the GP that day and then came back with antibiotics as well for what was diagnosed as an upper respiratory tract \\
infection. And he was really grateful that he did the test and that he was able to go see his GP...if he had...not gone to see a doctor, \\
perhaps he may have ended up in the emergency room because of complications of an upper respiratory tract infection that had gone \\
untreated." (PO10-E) \\
"I did have someone who had been to the doctor already. They felt unwell for quite a few weeks, but the doctor just sent them away and \\
said, "Obviously, it's just a virus. You don't need antibiotics." But after doing the test, it was elevated significantly, so they were able \\
to then go back to the doctor with the form and with an explanation of how antibiotics may be appropriate." (PO4-B)
\end{tabular}


make an informed decision about whether antibiotics were appropriate for them.

Given the global antimicrobial resistance crisis [37], pharmacists have an important role in minimising the inappropriate use of antimicrobials. Targeted interventions, such as POC CRP testing in community pharmacies, could have a large impact on reducing antimicrobial consumption, especially for RTIs. Pharmacists perceived 'the service' contributed to AMS. A major barrier to the implementation of AMS in community pharmacy is the lack of access to patient's records and laboratory data. CRP POC testing along with access to the national MyHealthRecord (national online summary of health information of an individual) [38] will help to address this barrier [39]. Information may not be complete due to the autonomy of the individual to not have certain health information recorded.

Most patients with acute RTIs do not benefit from antibiotic therapy [40-42]. However, antibiotics are frequently prescribed for consumers presenting to their GP [43-45]. Although pharmacists recognised that AMS was important to prevent unnecessary antibiotic prescriptions, in cases where CRP values were higher than expected, pharmacists were able to confidently refer consumers to their GP in a timely manner. Further, results of CRP testing could justify antibiotic use in consumers reluctant to take prescribed antibiotics.

Internationally, many pharmacies provide on-site preventative care services [46]. In Australia, several studies have reported positive outcomes following evaluation of community pharmacist experiences providing disease state management services, including delivery of a specialist asthma service [47], atrial fibrillation screening [48], and POC testing as part of hyperlipidaemia [26] and anticoagulant monitoring [28]. In this study, pharmacists perceived ease of accessibility to pharmacies as an important aspect facilitating uptake of pharmacy services, which has been previously reported [31, 49]. It seemed that the success of 'the service' was related to the pharmacist's engagement with the consumer. Had 'the service' been devolved to an assistant, it may have impacted on perceived professionalism. Hence, if 'the service' became widely available and was adequately remunerated, it would not be recommended to delegate CRP POC testing tasks to untrained or semi trained staff members.

Implementing a new service is not without challenges and requires careful planning and testing to ensure sustainability [50, 51]. Previous studies investigating the implementation of professional or enhanced services in Australian community pharmacy over many years have identified a range of common barriers and facilitators [2, $4,33,50,51]$. This study demonstrated some commonalities in barriers and facilitators for the provision of a CRP testing service.
Facilitators to service provision includes building rapport with physicians, pharmacy layout to ensure availability of a private or designated area for the service, adequate remuneration, consumer demand for the service, having adequate staff, good communication and teamwork, and having external support when needed [22,33,50]. While the methodology of the feasibility study addressed some of these factors including availability of a designated area and external support, participating pharmacists identified some of the other facilitators, including enhanced relationships with GPs and having a supportive team, which were also identified in a recent systematic review, investigating factors influencing national implementation of innovations within community pharmacy [33].

Although POC testing services provide opportunities to pharmacies to expand their services to improve the prevention and treatment of infectious diseases [46], deficits in pharmacist training and education [46], pharmacist time constraints, staff shortages, lack of return on investment/ inadequate remuneration and lack of access to medical records have been reported as barriers to service implementation (when the pilot study was conducted, the MyHealthRecord was not yet fully launched, but as My Health Record is fully integrated, there may be some access to medical records) [4]. In this study, perceived barriers included inadequate remuneration to justify employing multiple pharmacists at one time, as the walk-in nature of 'the service' made it difficult to predict when busy times were likely to occur. This has been reported in other studies [4, 22, 52]. Despite the availability of two pharmacists, competing demands, such as the provision of influenza vaccinations during the peak influenza season, were also reported to be a barrier and a contributor to erratic recruitment. Pharmacists had conflicting views as to who should pay for 'the service' if it was implemented; with some pharmacists suggesting a user-pay system, while others stated a service fee should be covered by Medicare, Australia's publically funded universal health insurance scheme.

As this was a pilot study, pharmacists commented that there was excess documentation that needed to be completed for every consumer who was provided with 'the service'. If 'the service' was implemented in routine practice, documentation would be reduced.

Studies investigating factors affecting the implementation of POC CRP in GP clinics identified similar themes to this study. Albeit the difference in primary care setting, certain factors that could impede the implementation of POC CRP were consistent and include staffing and cost while factors that could facilitate the implementation include confidence in clinical decision making and improvement in provider and patient engagement. [22].

The wider feasibility study of which this qualitative study formed a part, was designed as to pilot the POC CRP 
testing service in a small number of purposively selected community pharmacies, resulting in a small sample size, a potential limitation of the study, although a census sample was interviewed. Involvement of researchers with extensive experience in qualitative research added to the credibility and trustworthiness of the study. All participants initially underwent training to ensure they had the appropriate knowledge and skills for POC CRP testing (information on training has been reported elsewhere and is currently under review). This may have contributed to the relatively narrow spectrum of viewpoints. Nevertheless, several common themes emerged, which were supported by other studies investigating barriers and facilitators of service implementation. Reflection on the clinical and operational outcomes of the larger feasibility study [25], and participants' responses to the post-pilot questionnaire, provided evidence of credibility and triangulation. Nonetheless, recruitment of participants from within the confines of the feasibility study (in the interest of credibility, the participants had lived experience of providing the service) means that the findings should be cautiously generalised to the whole community pharmacy population. As this study was done prior to COVID-19, this would likely be another barrier identified especially with people with RTI symptoms presenting to community pharmacies. Further research is required involving a large mixed methods study to evaluate the requirements for full implementation in community pharmacies.

\section{Conclusion}

Pharmacists perceived the POC CRP testing service to be valuable in clinical decision making in the management of RTIs and potentially reducing inappropriate antibiotic use. The test was simple, reliable, fast and accurate although time constraints and competing demands were perceived as barriers to service provision. Although there is a perceived public need for POC CRP testing in Australian community pharmacies, adequate remuneration, potentially through government funding, is essential for successful implementation and delivery. While this study focussed on a POC CRP testing service, the lessons learnt are relevant in implementation of pharmacy POC testing services more broadly.

Acknowledgements The authors would like to acknowledge all of the pharmacists who participated in interviews as part of the study.

Author contributions PC, LC, JH, RI, YPL, KP, RP, BS and TFS contributed to the study conception and design. A semi-structured interview tool was developed by PC, LC, JH, RI, YPL, KP, RP, BS and TFS. All interviews were conducted by RI. Data analysis was performed by TFS and PC. The first draft of the manuscript was written by PC and reviewed by all authors. All authors read and approved the final manuscript.
Funding This work was supported by the J M O'Hara Research Fund managed by the Pharmaceutical Society of Western Australia.

Data availability Raw data available on request.

Code availability Not applicable.

Conflicts of interest None.

Ethics approval This study was approved by the Curtin University Human Research Ethics Committee (HRE2019-0139; 21 March 2019) and registered on the Australian New Zealand Clinical Trials Registry (ACTRN12619000965101).

Consent to participate All pharmacists interviewed provided written informed consent for their involvement in all aspects of the study.

\section{References}

1. Sim TF, Hattingh HL, Sunderland B, et al. Effective communication and collaboration with health professionals: a qualitative study of primary care pharmacists in Western Australia. PLoS ONE. 2020;15(6):e0234580.

2. McMillan SS, Wheeler AJ, Sav A, et al. Community pharmacy in Australia: a health hub destination of the future. Res Soc Adm Pharm. 2013;9(6):863-75.

3. Patwardhan PD, Amin ME, Chewning BA. Intervention research to enhance community pharmacists' cognitive services: a systematic review. Res Soc Adm Pharm. 2014;10(3):475-93.

4. Sim TF, Wright B, Hattingh L, et al. A cross-sectional survey of enhanced and extended professional services in community pharmacies: a pharmacy perspective. Res Soc Adm Pharm. 2019;16(4):511-21.

5. Buss VH, Shield A, Kosari S, et al. The impact of clinical services provided by community pharmacies on the Australian healthcare system: a review of the literature. J Pharm Policy Pract. 2018;11(1):22. https://doi.org/10.1186/s40545-018-0149-7.

6. Nazar H, Nazar Z. Community pharmacy minor ailment services: Pharmacy stakeholder perspectives on the factors affecting sustainability. Res Soc Adm Pharm. 2019;15(3):292-302.

7. Rutter P. Role of community pharmacists in patients' self-care and self-medication. Integr Pharm Res Pract. 2015;4:57-65.

8. Cooke J, Llor C, Hopstaken R, et al. Respiratory tract infections (RTIs) in primary care: narrative review of $\mathrm{C}$ reactive protein (CRP) point-of-care testing (POCT) and antibacterial use in patients who present with symptoms of RTI. BMJ Open Resp Res. 2020;7(1):e000624.

9. Australian Commission on Safety and Quality in Health Care (ACSQHC). AURA 2017: second Australian report on antimicrobial use and resistance in human health: ACSQHC Sydney; 2017 [Available from: https://www.safetyandquality.gov.au/sites/ default/files/2019-05/aura-2017-second-australian-report-onantimicrobial-use-and-resistance-in-human-health.pdf. Accessed 01.11.21]. ISBN: 978-1-925224-87-0.

10. Therapeutic Guidelines: Antibiotic [Internet]. Therapeutic Guidelines Limited. 2020. Available from: https://tgldcdp-tg-org-au. dbgw.lis.curtin.edu.au/fulltext/tglcontent/quicklinks/NPS-Medic ineWise-RTI-Action-Plan--1-.pdf. Accessed 01.11.21.

11. Bruyndonckx R, Coenen S, Hens N, et al. Antibiotic use and resistance in Belgium: the impact of two decades of multi-faceted campaigning. Acta Clin Belg. 2020. https://doi.org/10.1080/17843 286.2020.1721135. 
12. World Health Organisation. Antimicrobial Resistance 2020 [Available from: https://www.who.int/news-room/fact-sheets/ detail/antimicrobial-resistance. Accessed 01.11.21].

13. Klein EY, Van Boeckel TP, Martinez EM, et al. Global increase and geographic convergence in antibiotic consumption between 2000 and 2015. PNA S USA. 2018;115(15):E3463-70.

14. Jeffs L, McIsaac W, Zahradnik M, et al. Barriers and facilitators to the uptake of an antimicrobial stewardship program in primary care: a qualitative study. PLoS ONE. 2020;15(3):e0223822.

15. Aabenhus R, Jensen JU, Jørgensen KJ, et al. Biomarkers as pointof-care tests to guide prescription of antibiotics in patients with acute respiratory infections in primary care. Cochrane Database Syst Rev. 2014;11:Cd010130

16. Sproston NR, Ashworth JJ. Role of C-reactive protein at sites of inflammation and infection. Front Immunol. 2018;9:754.

17. Du Clos TW, Mold C. C-reactive protein. Immunol Res. 2004;30(3):261-77.

18. Eley CV, Sharma A, Lee H, et al. Effects of primary care C-reactive protein point-of-care testing on antibiotic prescribing by general practice staff: pragmatic randomised controlled trial, England, 2016 and 2017. Eurosurveillance. 2020;25(44):1900408.

19. Little P, Stuart B, Francis N, et al. Effects of internet-based training on antibiotic prescribing rates for acute respiratory-tract infections: a multinational, cluster, randomised, factorial, controlled trial. Lancet. 2013;382(9899):1175-82.

20. Cooke J, Butler C, Hopstaken R, et al. Narrative review of primary care point-of-care testing (POCT) and antibacterial use in respiratory tract infection (RTI). BMJ Open Respir Res. 2015. https:// doi.org/10.1136/bmjresp-2015-000086).

21. Hughes A, Gwyn L, Harris S, et al. Evaluating point-of-care C-reactive protein testing in a general practice. Clin Pharm. 2016;8:309-18.

22. Huddy JR, Ni MZ, Barlow J, et al. Point-of-care $\mathrm{C}$ reactive protein for the diagnosis of lower respiratory tract infection in NHS primary care: a qualitative study of barriers and facilitators to adoption. BMJ Open. 2016. https://doi.org/10.1136/bmjop en-2015-009959).

23. Minnaard MC, Van De Pol AC, De Groot JA, et al. The added diagnostic value of five different $\mathrm{C}$-reactive protein point-of-care test devices in detecting pneumonia in primary care: a nested casecontrol study. Scand J Clin Lab Inv. 2015;75(4):291-5.

24. Wakeman M, Cork T, Watwood D. Point-of-care C-reactive protein testing in community pharmacy to deliver appropriate interventions in respiratory tract infections. Clin Pharm. 2018;10:158-72.

25. Sim TF, Chalmers L, Czarniak P, et al. Point-of-care C-reactive protein testing to support the management of respiratory tract infections in community pharmacy: a feasibility study. Res Soc Adm Pharm. 2021;17(10):1719-26.

26. Aslani $\mathrm{P}, \mathrm{Chen} \mathrm{T}$, Whitehead $\mathrm{P}$, et al. A community pharmacist delivered therapeutics outcome monitoring service for hyperlipidaemia-(Project Number 2002-024) 2006. [Available from: https://6cpa.com.au/wp-content/uploads/A-community-pharm acist-delivered-therapeutics-outcome-monitoring-service-forhyperlipidemia-final-report.pdf. Accessed 01.11.21].

27. Krass I, Taylor SJ, McInman AD, et al. Community pharmacists' role in the continuity of care in type 2 diabetes: an evaluation of a model 2004. [Available from: https://6cpa.com.au/wpcontent/uploads/An-integrated-model-for-disease-state-manag ement-DSM-in-diabetes-collaboration-of-the-community-pharm acist-and-GP-in-continuity-of-care-final-report.pdf. Accessed 01.11.21].

28. McLachlan A, Spindler M, Fois R, et al. A community pharmacy based anticoagulant management service 2002. [Available from: https://6cpa.com.au/wp-content/uploads/A-community-pharm acy-based-anticoagulant-management-service-final-report.pdf 1 . Accessed 01.11.21].

29. Pharmaceutical Society of Australia. Pharmacists in 2023: For patients, for our profession, for Australia's health system Canberra: PSA; 2019 [Available from: https://www.psa.org.au/ wp-content/uploads/2019/02/Pharmacists-In-2023-digital.pdf. Accessed 01.11.21].

30. International Pharmaceutical Federation. FIP Reference Paper on Self Care The Hague: FIP; 2017. [Available from: https://www. fip.org/file/1590. Accessed 01.11.21].

31. Hattingh L, Sim TF, Sunderland B, et al. Successful implementation and provision of enhanced and extended pharmacy services. Res Soc Adm Pharm. 2020;16(4):464-74.

32. Nordin N, Hassali M, Sarriff A. A global picture of extended pharmacy services, perceptions and barriers toward its performance: a systematic review. Asian J Pharm Clin Res. 2017;10(11):417-27.

33. Weir NM, Newham R, Dunlop E, et al. Factors influencing national implementation of innovations within community pharmacy: a systematic review applying the consolidated framework for implementation research. Implement Sci. 2019;14(1):1-16.

34. Czarniak P, Krass I, Sunderland B, et al. Factors associated with the intensity of government remunerated and unremunerated service provision in community pharmacies. Res Soc Adm Pharm. 2021;17(9):1614-22.

35. Patton MQ. Qualitative research and evaluation methods: integrating theory and practice. 4th ed. California: SAGE Publishing; 2015. (978-1-4129-7212-3).

36. Tong A, Sainsbury P, Craig J. Consolidated criteria for reporting qualitative research (COREQ): a 32-item checklist for interviews and focus groups. Int J Qual Health Care. 2007;19(6):349-57.

37. Church NA, McKillip JL. Antibiotic resistance crisis: challenges and imperatives. Biologia. 2021: pp. 1-16.

38. Australian Government Australian Digital Health Agency. My Health Record 2021 [Available from: https://www.myhealthre cord.gov.au/. Accessed 01.11.21].

39. Saha SK, Barton C, Promite S, et al. Knowledge, perceptions and practices of community pharmacists towards antimicrobial stewardship: a systematic scoping review. Antibiotics. 2019;8(4):263. https://doi.org/10.3390/antibiotics8040263.

40. Smith SM, Fahey T, Smucny J, et al. Antibiotics for acute bronchitis. Cochrane Database Syst Rev. 2014. https://doi.org/10.1002/ 14651858.CD000245.pub3).

41. Little P, Stuart B, Moore M, et al. Amoxicillin for acute lowerrespiratory-tract infection in primary care when pneumonia is not suspected: a 12-country, randomised, placebo-controlled trial. Lancet Inf Dis. 2013;13(2):123-9.

42. Butler CC, Hood K, Verheij T, et al. Variation in antibiotic prescribing and its impact on recovery in patients with acute cough in primary care: prospective study in 13 countries. BMJ. 2009. https://doi.org/10.1136/bmj.b2242.

43. Goossens H, Ferech M, Vander Stichele R, et al. Outpatient antibiotic use in Europe and association with resistance: a cross-national database study. Lancet. 2005;365(9459):579-87.

44. Chua K-P, Fischer MA, Linder JA. Appropriateness of outpatient antibiotic prescribing among privately insured US patients: ICD10-CM based cross sectional study. BMJ. 2019. https://doi.org/ 10.1136/bmj.k5092.

45. Little P, Dorward M, Warner G, et al. Importance of patient pressure and perceived pressure and perceived medical need for investigations, referral, and prescribing in primary care: nested observational study. BMJ. 2004;328(7437):444. https://doi.org/ 10.1136/bmj.38013.644086.7C.

46. Gubbins PO, Klepser ME, Dering-Anderson AM, et al. Pointof-care testing for infectious diseases: opportunities, barriers, and considerations in community pharmacy. J Am Pharm Assoc. 2014;54(2):163-71. 
47. Emmerton LM, Smith L, LeMay KS, et al. Experiences of community pharmacists involved in the delivery of a specialist asthma service in Australia. BMC Health Serv Res. 2012;12(1):1-10.

48. Lowres N, Krass I, Neubeck L, et al. Atrial fibrillation screening in pharmacies using an iPhone ECG: a qualitative review of implementation. Int J Clin Pharm. 2015;37(6):1111-20.

49. Hattingh HL, Sim TF, Parsons R, et al. Evaluation of the first pharmacist-administered vaccinations in Western Australia: a mixed-methods study. BMJ Open. 2016;6(9):e011948.

50. Roberts AS, Benrimoj SI, Chen TF, et al. Practice change in community pharmacy: quantification of facilitators. Ann Pharmacother. 2008;42(6):861-8.

51. Moullin JC, Sabater-Hernández D, Benrimoj SI. Qualitative study on the implementation of professional pharmacy services in Australian community pharmacies using framework analysis. BMC Health Serv Res. 2016;16(1):1-13.

52. Berbatis CG, Sunderland VB, Joyce A, et al. Enhanced pharmacy services, barriers and facilitators in Australia's community pharmacies: Australia's National pharmacy database project. Int J Pharm Pract. 2007;15(3):185-91.

Publisher's Note Springer Nature remains neutral with regard to jurisdictional claims in published maps and institutional affiliations. 